\title{
Sobre a Tradução Intersemiótica de Gertrude Stein
}

\section{Daniella Aguiar $^{1}$ Adriano Mattos Correia ${ }^{2}$ Edson Zampronha ${ }^{3}$ João Queiroz ${ }^{4}$}

\section{Resumo:}

Descrevemos neste artigo um experimento de tradução intersemiótica, o espetáculo [5.sobre.o.mesmo]. Trata-se de uma tradução para dança de um fragmento da prosa de Gertrude Stein, "Orta or One Dancing". O espetáculo pode ser descrito como um "laboratório de tradução" criativa em que foram exibidos os resultados de cinco criadores-intérpretes, além dos resultados do músicoedoarquiteto.Oprincipalobjetivodoprojeto foi tornar explícito os processos de recriação da obra de Stein, ao mostrar comparativamente diferentes repertórios e estratégias, sobre o mesmo texto.

Plavras-chave: tradução intersemiótica, dança contemporânea, Gertrude Stein.

\section{Abstract:}

Here we describe an experiment on intersemiotic translation: [5.sobre.o.mesmo]. This dance piece translates a literary portrait by Gertrude Stein, "Orta or One Dancing". It can be described as a creative "translation lab" exhibiting the results of independent translations by five dancers/choreographers, also by the composer and the architect. The main objective of this project was to make explicit the processes of Stein's text recreation, when it comparatively exhibits different repertoires and strategies, on the same source.

Key-words: intersemiotic translation, contemporary dance, Gertrude Stein.

1 Doutora, Programa de Pós-Graduação em Letras: Estudos Literários, UFJF.

2 Mestre, Escola de Arquitetura, UFMG.

3 Doutor, Música, Universidad Internacional Valenciana.

4 Doutor, Instituto de Artes e Design, UFJF. 


\section{Introdução}

De acordo com Roman Jakobson (1969, p. 65), a tradução intersemiótica "consiste na interpretação dos signos verbais por meio de sistemas de signos não-verbais". O linguista russo foi o primeiro a elaborar um conceito para este tipo de relação, entre sistemas de signos verbais e nãoverbais. $\mathrm{O}$ termo posteriormente adquiriu maior abrangência, e atualmente é utilizado para designar relações entre sistemas de diversas naturezas, não estando mais confinado à interpretação de signos verbais (Gorlée, 2007; Clüver, 1997, p. 43; Plaza, 1987).

Na história da dança é enorme a influência das adaptações ou traduções intersemióticas com foco em literatura, dos clássicos de Petipa ${ }^{1}$, no século XIX, às experiências mais contemporâneas. Considerada a importância do fenômeno, e a frequência com que é praticado em dança, é surpreendente que ainda seja tratado tão parcimoniosamente, em termos teóricos, destituído de uma metalinguagem crítica apropriada (ver Aguiar, 2013), que aparece predominantemente em releases e programas de espetáculo.

O propósito deste artigo é descrever um experimento recente de tradução intersemiótica -- [5.sobre.o.mesmo]. [5] é uma tradução para dança de um fragmento da prosa da escritora norteamericana Gertrude Stein, mais especificamente de um retrato da escritora, "Orta or one dancing" (“Orta ou alguém dançando"). O espetáculo estreou no Teatro Vila Velha, em Salvador, onde esteve em cartaz entre 27/02 e 08/03 de 2010². O projeto pode ser descrito como um laboratório de tradução criativa em que foram exibidos, conjuntamente, os resultados desenvolvidos por cinco criadores-intérpretes, além do músico-compositor e do arquiteto envolvidos na construção de objetos sonoros e do espaço cênico. O principal objetivo do projeto foi tornar explícitos os processos de recriação, ao exibir comparativamente diferentes interesses, repertórios, e estratégias, sobre o mesmo texto literário. Em outros termos, [5] exibiu cinco versões, adaptações ou recriações para dança, desenvolvidas independentemente, por cinco dançarinos (Clara Trigo, Daniella Aguiar, Olga Lamas, Tiago Ribeiro, Rita Aquino), de um texto literário ("Orta”), pelo compositor Edson Zampronha (música original) e pelo arquiteto Adriano Mattos (espaço e iluminação).

A ideia pode ser assim sumarizada: o mesmo fragmento de Stein, traduzido para o português por Luci Colin (ver apêndice), acompanhado de textos críticos, foi submetido aos criadores. Por diversos meses eles tiveram autonomia e independência em suas recriações deste fragmento. Foi pedido para que não se comunicassem uns com os outros durante o período em que estivessem criando. Se respeitada esta restrição, acreditávamos que haveria boa possibilidade de examinarmos, comparativa e criticamente, as opções estratégicas de cada criador-intérprete, do músico e do arquiteto, sobre o mesmo texto traduzido ou recriado.

Construímos, portanto, um ambiente em que se identificariam as decisões sobre o que é mais relevante, e sobre como recriar o que é considerado relevante, por cada um dos criadores-intérpretes. Tratava-se de uma boa suposição que o resultado, se ele exibisse alguma consistência interna, e

1 Ao final do século XIX, Marius Petipa (1818-1910) coreografava, nos Teatros Imperiais da Rússia, seus mais famosos balés. Ele recriou os contos de fadas do francês Charles Perrault "A bela adormecida" (1890) e "Barba Azul" (1896); o conto de E.T.A. Hoffman, "O Quebra-Nozes e o Rei dos Camundongos" (1816), através da adaptação de Alexandre Dumas em 1844, no balé "O Quebra-Nozes" (1892); o conto, "Der geraubte Schleier", do autor alemão Johann Karl August Musäus no balé "O lago dos cisnes" (1877-1895); entre outros.

2 Ficha técnica: Concepção e coordenação: João Queiroz / Criação e interpretação: Clara Trigo, Daniella Aguiar, Olga Lamas, Rita Aquino, Tiago Ribeiro / Música original: Edson Zampronha / Espaço e Luz: Adriano Mattos Corrêa / Operação de luz: Rivaldo Rio / Design: Phillip Rodolfi / Produção e Assessoria de Imprensa: Paula Carneiro / Assistente de Produção: Daniella Aguiar / Tradução de Gertrude Stein: Luci Collin / Fotografia: Adriano Mattos Corrêa / Fotografia de Divulgação: Aldren Lincon. 
conjunta, seria principalmente porque o signo-fonte (a obra traduzida de Gertrude Stein) teria as mesmas propriedades consideradas relevantes pelos criadores-intérpretes, e porque tais propriedades seriam tratadas (recriadas) através de materiais e estratégias similares, em termos de atividades motoras, organização sonora e espacial.

É um tipo de protocolo. Fixamos e controlamos um pequeno numero de ações que permitisse fazer comparações diretas entre os resultados. Nossa suposição é que ficariam bastante claras as decisões dos criadores, que poderiam convergir ou divergir consideravelmente do signo-fonte traduzido. Essa é uma questão com muitas implicações: que tipo de decisão é tomada por cada dançarino e criador ao ser exposto ao mesmo signo-fonte (a obra traduzida, neste caso literária)? Uma vez que são sistemas semióticos muito distintos, pode-se especular em diversas direções. Um criador pode considerar certa ambiência psicológica, ou um personagem particular, se ele existir, ou uma estrutura que deseja "isolar" ou enfatizar, etc. Uma obra recriada é feita de muitos "componentes", e os criadores são muito diferentes. É certo que há aproximações notáveis, envolvendo formas de treinamento mais frequentes em uma geração de dançarinos, ou certas preferências fixadas por um período. Mas ainda assim são muito diferentes. O resultado é uma superposição de desenvolvimentos criados com autonomia pelos dançarinos, pelo músico-compositor e pelo arquiteto.

Observamos, portanto, um tipo de parataxe que instaura uma lógica de coordenação que opera em todos os domínios do espetáculo, e em cada evento. Para Pignatari (2004, p. 188), a parataxe, em oposição à hipotaxe, pode ser descrita como um princípio de organização do pensamento e da linguagem associado à analogia, à construção des-hierarquizada, sincrônica e coordenativa entre as partes de um discurso ou texto - "É a luta entre a hipotaxe hegemônica e dominante contra a parataxe colonizada e dependente, a primeira a comando de um Hierarkhos, o chefe-sagrado, a segunda sob o descomando de Anarkhos, o sem chefe, por baixo, mas permanentemente subversivo, pois que é impossível eliminá-lo". Este princípio baseou a interação entre os dançarinos, nas situações em que atuavam improvisadamente, e também entre os níveis que organizavam o espetáculo, incluindo a música e o ambiente espacial. Todos os eventos observados eram independentes já que não havia qualquer relação de causalidade estrita entre eles, assim como entre a música e as atividades motoras ou entre a luz e estas atividades. Tratava-se, todo o tempo, de um conjunto de eventos coincidentes. As "aproximações", ou similitudes, de qualquer ordem, não seriam produto de indeterminação, mas de restrições exercidas pelo texto-fonte, que é o fragmento do retrato de Stein.

Nas seções seguintes, descrevemos os materiais usados, as relações entre os criadores, e sobre o signo-fonte recriado.

\section{Sobre o signo-fonte: Orta or One Dancing}

Even if one was one she might be like some other one. She was like one and then was like another one and then was like another one and then was like another one and then was one who was one having been one and being one who was one then, one being like some.

Even if she was one and she was one, even if she was one she was changing. She was one and was then like some one. She was one and she had then come to be like some other one. She was then one and she had come then to be like some other one. She was then one and she had come then to be like some other one. She was then one and she had come then to be like a kind of a one. 


\section{Daniella, Adriano, Edson e João}

Even if she was one being one, and she was being one, she was one being one and even if she was one being one she was one who was then being a kind of a one (Stein, 1998 [1912], p.285).

Estes são os primeiros parágrafos de um dos retratos literários feitos por Stein de artistas influentes, seus contemporâneos. O primeiro aspecto notável é a falta de referência a qualquer sujeito, característica de muitos de seus retratos ${ }^{3}$. O título, “Orta or One Dancing”, sugere que se trata de alguém dançando -- one dancing pode ser traduzido literalmente por alguém dançando. Embora não haja qualquer nomeação direta, sabe-se que este é um retrato da dançarina Isadora Duncan ${ }^{4}$. De acordo com Bridgman (1970, p. 96), os títulos provisórios encontrados nos manuscritos são "Orta Davray", "Alma Davray" e "Isadora Dora Do", este "último sugere que o retrato tinha conexão com Isadora Duncan, que os Steins conheciam bem".

A falta de referência direta indica algumas características importantes deste retrato. Não há, em primeiro lugar, aparente necessidade de saber algo sobre o referente. Este fato fornece ao retrato uma qualidade de anonimato, conduzindo a atenção do leitor para a própria linguagem, para a forma de elaboração do retrato escrito, ao invés de sua relação com o retratado, o objeto do retrato. Este simples ato, de não nomear o retrato, confere liberdade à escritora e modifica as possibilidades de leitura, além de alterar a relação entre retrato e retratado.

Ao direcionar a atenção do leitor para a linguagem, e repetir alguns procedimentos formais em retratos de diferentes personalidades, a escritora parece criar um procedimento padrão. Para Bridgman (1970, p. 96), por exemplo, em alguns dos primeiros retratos “[...] Gertrude Stein tentou eliminar tantas especificidades quanto possível para criar uma superfície uniforme da prosa". Podemos listar algumas características gerais destes experimentos linguísticos, como o uso de poucos vocábulos e a consequente repetição deles, a repetição das frases, e também dos parágrafos, com alterações sutis, e o uso dos verbos no gerúndio. Apesar de reconhecer tal unidade em termos de procedimentos formais nos retratos da primeira fase, outros autores destacam a curiosa relação de identidade entre retrato e retratado. De acordo com Walker (1984, p. 99),

A virtuosidade rítmica de 'Orta or One Dancing' funde totalmente significado lexical e figuração icônica. [...] Por todo este retrato de Isadora Duncan, a dançarina e sua dança são poderosamente representadas no jogo rítmico de significantes que legitima os compassos móveis da dança. [...] Em 'Orta' ela explorou a liberdade rítmica de Isadora Duncan em sua própria mídia.

De acordo com o autor, através dos retratos, Stein desvenda personagens individuais em uma forma literária dinâmica. Ao invés de rotular a personalidade de cada sujeito, os retratos inscrevem tais sujeitos através de sua padronização material, reforçando e complementando o significado lexical (Walker, 1984, p. 98-99).

3 De acordo com Steiner (1978, p. 66), apesar dos primeiros retratos de Stein serem mais consistentes com as normas do gênero, "Ada" e "Orta or One Dancing" usam nomes ficcionais para seus retratados. Neste caso, segundo a autora, informações externas ao retrato são necessárias para confirmar se o retratado é uma pessoa real, e quem seria esta pessoa.

$4 \quad$ Angela Isadora Duncan (1877-1927) se tornou uma das mais famosas dançarinas no início do século XX ao criar um estilo antagônico à dança cênica vigente na época, o balé clássico. Sua dança foi inspirada na Grécia Antiga a partir do teatro e imagens de dança dos vasos gregos. Ela dançava de pés descalços, opondo-se ao que considerava a rigidez das sapatilhas de pontas da técnica clássica. 
Descrevemos, na próxima seção, as ideias relacionadas à concepção dos criadores-intérpretes, do músico e do arquiteto. O propósito desta seção é indicar as opções e alternativas criadas por cada criador-intérprete sobre o mesmo texto-fonte.

\section{Dança: criadores-intérpretes}

Clara Trigo e Tiago Ribeiro trabalharam na elaboração de posições e posturas corporais, indefinidamente combinadas. Em outras palavras, eles criaram poucos elementos para serem repetidos em combinações diversas. Enquanto Trigo optou por um “quebra-cabeças de peças motoras" de mesmo tamanho e duração, utilizando apenas o plano baixo, Ribeiro trabalhou sobre um escopo de movimentos que incluía desde posturas mínimas com os dedos das mãos até movimentos amplos com os dois braços e as pernas abertos, em todos os níveis do espaço ${ }^{5}$.

Clara Trigo concentrou-se inicialmente na noção de "presente contínuo", tentando recriar tal propriedade através do que chamou de "rastros de movimento". Em seguida passou a atuar na estrutura do texto composto pela repetição e permutação de poucos componentes, ou seja, de poucos elementos repetidos em diversas combinações. Trigo realizou seus experimentos sobre transferências de peso corporal associados à repetição. Inicialmente, valeu-se de um repertório do sapateado flamenco, tentando criar pequenas variações de transferência de peso combinadas. Entretanto, o flamenco, segundo Trigo, tornara-se mais notável que a própria tradução. Segundo Trigo (comunicação pessoal),

A característica do texto que mais me impacta é a repetição com a diferença. As variações na repetição me levam a algumas imagens: Rastro, Vestígio, Visgo, Fractal, Bolhas dentro de bolhas dentro de bolhas dentro de bolhas, "Repetir, repetir até ficar diferente", Impalpável, Volátil. Depois de lê-lo algumas vezes, tive a necessidade de ter o texto audível, para ouvi-lo muitas vezes e entrar em contato por outro suporte e para poder me mover enquanto ouvia. Gravei o texto. Isso foi muito difícil! Na audição, foi incrível perceber outras dimensões de significado e de ritmo do texto. Pensando em ritmo e em repetição com diferença, me aparecem como estratégias de composição: transferência de peso e análise combinatória.

Estou nessa etapa:

Coleta de pequenos movimentos muito pouco "espetaculares" que derivam em um lugar bem diferente. Uso o texto falado como "mantra". Desde cedo no texto ela já não volta ao começo. Deformações contínuas. Sutis variações rítmicas. Importante levar em consideração o rigor do texto nas escolhas cênicas. Muito rigor na brincadeira das análises combinatórias, para não dar saltos. Mastigar e construir os elos de um lugar ao outro.

Dando sequência à investigação por meio de um número reduzido de elementos que se repetem, a dançarina criou diversas posições a partir de uma posição inicial (Fig. 1). O critério principal baseou-se no uso de um "mínimo" de articulações e grupos musculares. Além disso, Trigo pretendeu revelar o principal aspecto referencial do texto traduzido: uma mulher dançando. A ideia é que o encadeamento e a combinação dos componentes deveriam gerar contextos relacionados ao universo de referência da obra. Foram criados oito movimentos numerados para realizar uma espécie de "jogo de combinações" que, inicialmente, deveria ter início a partir de um jogador externo 5 Uma divisão do espaço frequentemente utilizada o separa em níveis: baixo, médio e alto. O nível baixo se refere à ocupação do espaço mais próximo ao chão; o médio é o espaço entre o chão e a posição em pé, e o alto se refere àquele espaço ocupado a partir da posição em pé e acima desta. 


\section{Cena 15}

\section{Daniella, Adriano, Edson e João}

propondo sequências de números, a fim de produzir desafios de execução. Diversas mudanças eliminaram o jogador externo e a necessidade de explicitar os números associados aos movimentos e às regras. A ideia foi apresentar as combinações de um modo surpreendente, gerando padrões corporais complexos, baseados em posições iniciais muito simples.
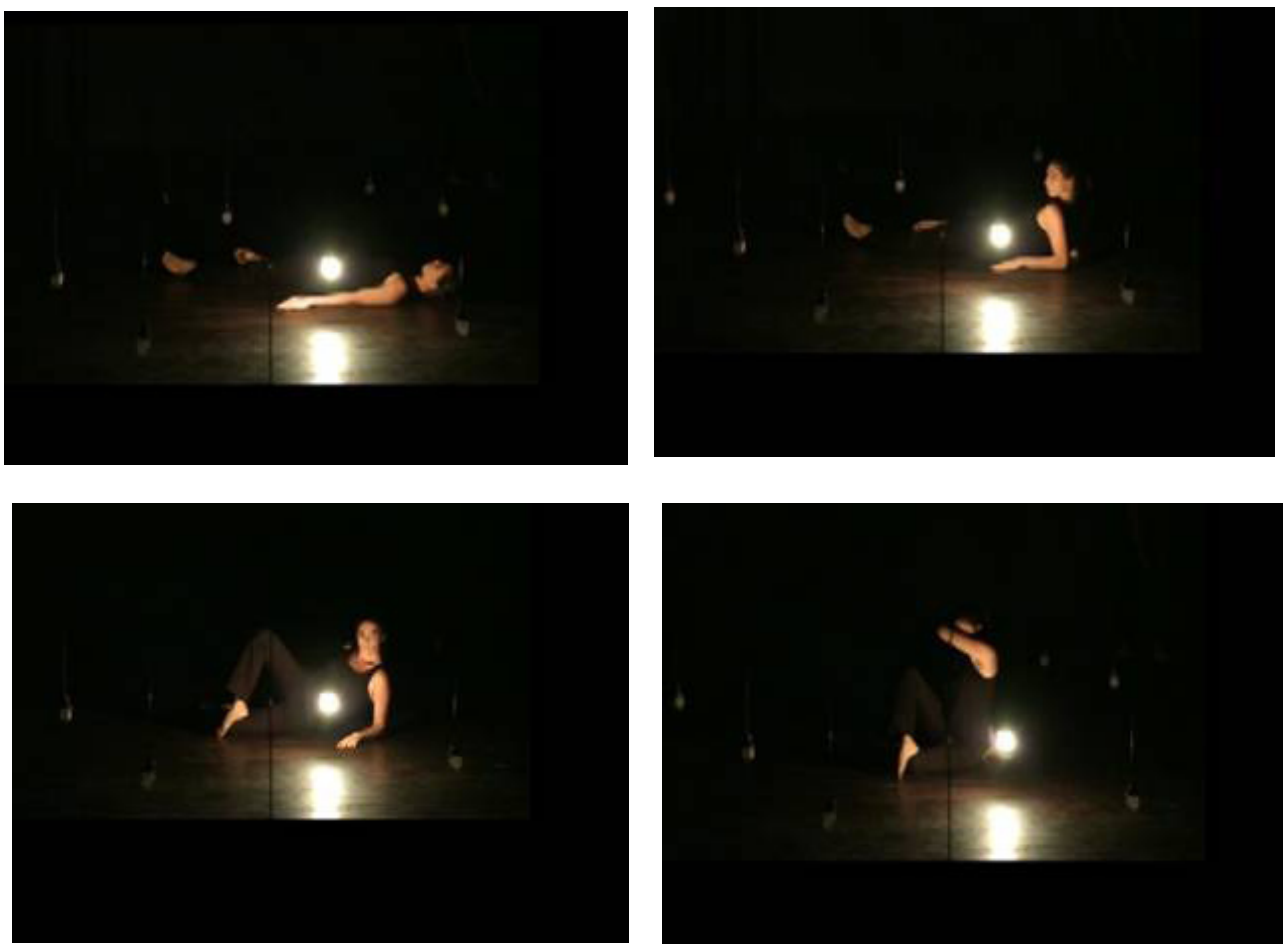

Figura 1. Sequência de movimentos de Trigo. (Frame de registro em vídeo).

Para Ribeiro, a primeira leitura produziu diversos objetos gráficos (Fig. 2), baseados em repetições rítmicas de um acervo limitado de vocábulos visuais.

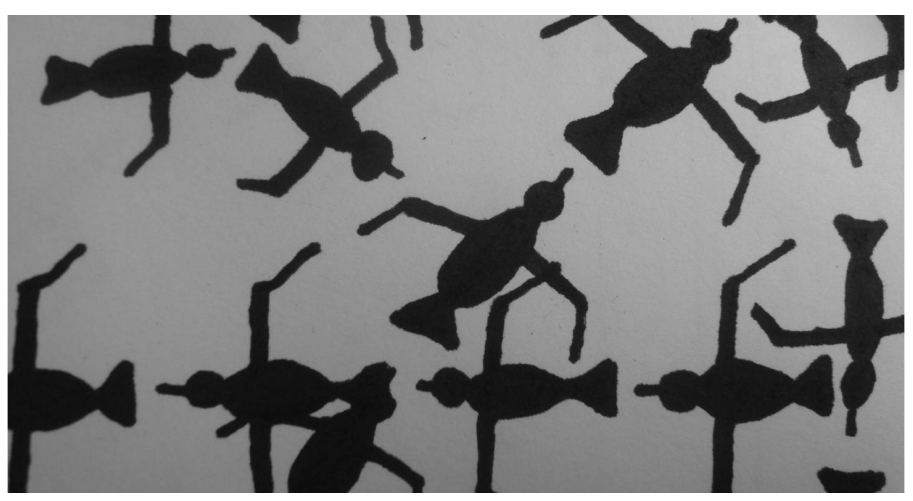

Figura 2. Desenho realizado por Tiago Ribeiro baseado na leitura do retrato de Gertrude Stein. 
Em viagem à Colômbia, Ribeiro desenvolveu um diário de viagem inspirado na escritura de Stein. Diferente dos outros criadores, Ribeiro fez uma profunda pesquisa contextual, a partir das autobiografias e de outros textos e livros da autora (e.g. "Paris - França”, "Autobiografia de todo mundo"). Quando iniciou a investigação motora, já possuía um extenso suporte bidimensional, que chegava a considerar mais "eficiente" que as gestualidades experimentadas. Ele também apropriou-se de outras referências, populares, como o maracatu, que terminou por não desenvolver (comunicação pessoal).

Seu material também concentrou-se na repetição de poucos vocábulos, similar aos desenvolvimentos de Trigo. Entretanto, seus "vocábulos em movimento" não foram construídos com referência a qualquer aspecto semântico do texto. Foram unidades de movimento, em sua maioria muito simples e pequenas (movimentos dos dedos das mãos), com algumas variações mais amplas (movimento de ajoelhar no chão) e outras unidades de repetição mais dinâmica (cabeça em movimento de rotação, ver Fig. 3).
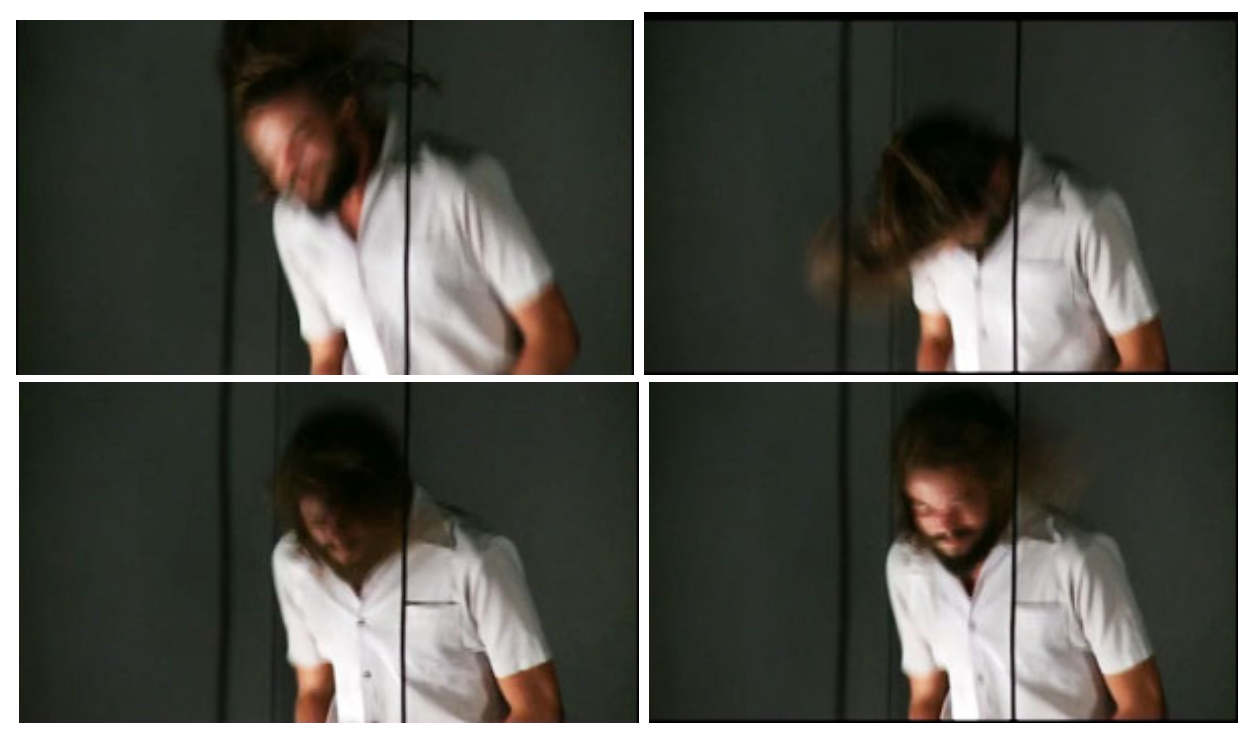

Figura 3. Sequência de movimentos de rotação da cabeça. (Frame de registro em vídeo).

Trigo e Ribeiro, portanto, se relacionaram com o retrato de Stein especialmente através da repetição de um número reduzido de vocábulos, não interessando sua ordem específica - em cada repetição os elementos (vocábulos) apareceram em diferentes sequências. Trigo e Ribeiro recriaram o princípio de densa repetição que relaciona os elementos vocabulares que observaram em "Orta".

Daniella Aguiar criou pequenos fragmentos ou núcleos, cada um deles com uma relação específica com a obra traduzida. Embora apresentados em uma ordem, eram materiais semiindependentes, que podiam ser apresentados em diferentes sequências. Os primeiros ensaios de Aguiar baseavam-se em vídeo-experimentos. Como Ribeiro, a dançarina procurou trabalhar inicialmente com outras mídias. O aspecto do texto mais acentuado nos vídeos foi a repetição de poucos elementos associados a mudanças semânticas ou de referência. Quando os estudos se deslocaram do vídeo para execução de padrões motores, o foco foi transferido para a ideia geral de insistência e presente contínuo. Assim, cada pequeno núcleo, apesar de independente, possuía uma forte relação intrínseca com os demais, pois eles eram estruturalmente similares. 
Em alguns momentos, Aguiar procurou traduzir a estratégia de Stein de recomeços sucessivos, apresentando uma ação que não se desenvolve temporalmente. Em outros, refez uma ação motora reiteradas vezes. Nos dois casos, refez a ação enfatizando, controladamente, diferenças que ocorrem em cada nova repetição. Sobre este aspecto, a dançarina realizou experimentos com uma ação que se repete ininterruptamente - "sentar-se ininterruptamente", "corrida com salto", "procurar um lugar no espaço", "tremer o tronco"; com ações que se repetem e recomeçam de diversos pontos da trajetória da ação - "passos de jazz", "pose de modelo", "braços de Isadora Duncan". Estes estudos, quase todos mantidos até a apresentação para a equipe, constituem o foco do trabalho de Aguiar. Sobre seus exercícios criativos, Aguiar comenta (com. pessoal):

- experimentos corporais: experimentei as noções de 'alargamento temporal' (prolongamento do tempo), insistência e repetição com a ação de sentar em uma cadeira. três tentativas. a mais interessante: sentar-se e arrumar-se sem que a ação de sentar termine. a ação se prolonga em um tempo bastante esgarçado porque a sua finalização não é feita, porque o arrumar-se perpetua-se.

Para o desenvolvimento de cada núcleo houve uma preocupação sobre que tipo de vocabulário corresponderia àquilo que Stein desenvolve no retrato. Ainda de acordo com sua descrição (com. pessoal):

A escolha do tipo de material corporal para a realização dos estudos de tradução do texto deveria amplificar as noções de ser/estar/existir e, ao mesmo tempo, criar o efeito de um presente que não se desenvolve.

Aspectos referenciais foram diretamente considerados, especialmente sobre Isadora Duncan, relacionados à "identidade", aos verbos "ser" e "existir". Aguiar realizou diversos estudos sobre a utilização dessas referências. Para isto, utilizou uma fotografia de Isadora Duncan em frente ao rosto, de diversas formas. A última versão deste estudo consistiu em impressões semitransparentes da mesma foto de Duncan sobrepostas e colocadas junto ao rosto da criadora, sentada em uma cadeira. Estas fotos eram retiradas sequencialmente e depositadas no colo da intérprete, de modo que a imagem, no início muito escura, tornava-se cada vez mais nítida, revelando ao final o rosto de Aguiar, misturado ao de Isadora. O propósito foi fazer referência à dançarina moderna, objeto do retrato de Stein e, ao mesmo tempo, identificá-la com a atual dançarina, tradutora do retrato de Stein. Além disso, referia-se ao fato de que o texto-fonte é um retrato, e não outro gênero.

Rita Aquino também trabalhou em fragmentos ou núcleos, de modo semelhante a Aguiar. Diversos núcleos estão baseados na repetição, nas diferentes maneiras de repetir o mesmo movimento e em recomeços sucessivos. Como Aguiar, Aquino realiza ações que se repetem e recomeçam em diversos pontos da trajetória da ação, e também realiza ações que se repetem ininterruptamente (Fig. 4). São exemplos deste último tipo de investigação: "mexer nos cabelos" e "linha de espasmos". Além disso, a dançarina trabalha com referência ao cubismo e à noção de múltiplas perspectivas sobre um mesmo objeto. Para tanto, utiliza objetos -- diversas xícaras brancas que são combinadas e empilhadas, formando pequenas esculturas e, de diferentes modos, são apresentadas ao público de diferentes pontos de vista. Como afirmado, Aquino considera que o objeto da obra de Stein é a linguagem visual do cubismo, e trabalha a partir desta referência. 

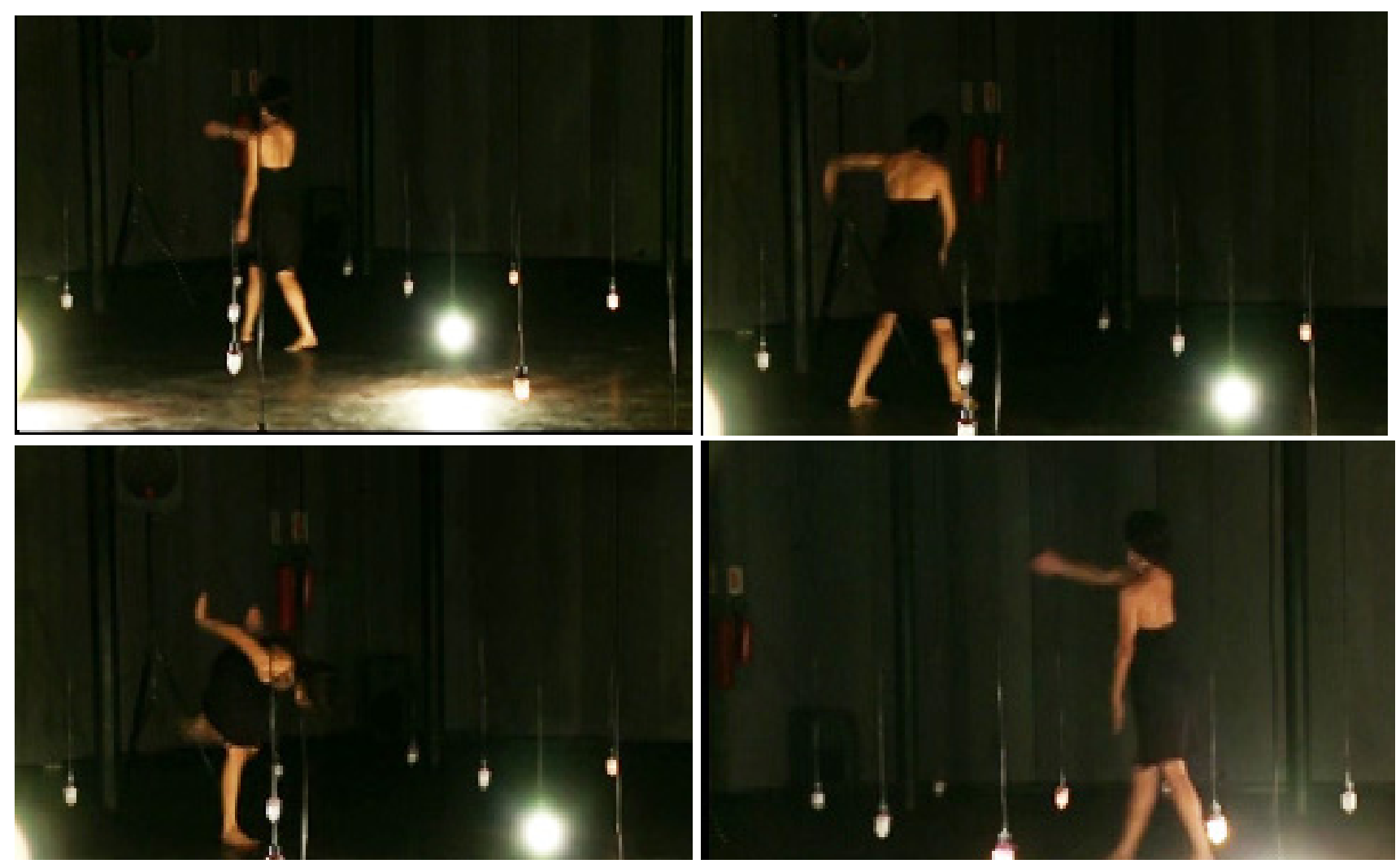

Figura 4. Aquino em ações que se repetem e recomeçam em diferentes momentos da trajetória. (Frame de registro em vídeo).

Aguiar e Aquino, embora criem em núcleos ou fragmentos semi-independentes, apresentam um trabalho de tradução coeso, pois suas partes estão relacionadas com a obra traduzida e entre si através de regras similares, determinadas pela obra fonte ${ }^{6}$.

Olga Lamas, diferentemente dos outros criadores, elaborou uma sequência fluida com começo, meio e fim, onde a ordem sequencial parece mais importante. De modo distinto também dos outros criadores, Olga estabelece uma relação mais metafórica e conceitual com o texto. Apesar disso, também cria momentos de repetição e recomeços sucessivos. Os objetos e artefatos que utiliza incluem espelhos, longas caminhadas, e um cigarro.

\section{Música}

A construção musical, de Edson Zampronha, partiu de quatro eventos sonoros permutados de forma irregular, uma analogia ao procedimento construtivo de Gertrude quanto ao restrito número de elementos. Estes quatro eventos são combinados para formar três grandes segmentos musicais, cada um dividido em duas partes. A primeira parte de cada segmento apresenta os quatro eventos sonoros (A, B, C e D), sempre permutados e variados. A segunda parte, no entanto, inclui somente três (A, C e D, por exemplo), de forma que é sempre interrompida ('truncada'). Esta assimetria

\footnotetext{
6 Deve-se notar que Aguiar e Aquino trabalharam conjuntamente no espetáculo ,e[dez episódios sobre a prosa topovisual de gertrude stein], também baseado em Stein, anterior ao [5], o que provavelmente se reflete na semelhança de suas investigações artísticas neste projeto.
} 
produz um rico desequilíbrio e um certo modo de complementaridade, já que o evento que falta na segunda parte ganha destaque em outra primeira parte. Além disso, cada evento é submetido a variações intrínsecas, de forma a apresentar inícios sucessivos, adições, subtrações, truncamentos, e também remissões a outros eventos, produzindo uma complexa interconexão.

Tal procedimento ocorre de modo similar na organização das notas, dos ritmos e das texturas, tanto na macro-forma musical quanto na microforma. Na microforma musical merece destaque a aplicação da estratégia de Stein de desdobrar as ideias a partir de um segmento inicial -- ela apresenta um segmento de texto, em seguida varia este segmento por subtração, inversão, truncamento, ampliação, e assim sucessivamente. Este procedimento é comparável àquele utilizado por Stravinsky, especialmente na Sagração da Primavera, de 1913, onde as experimentações sobre o ritmo são essenciais. Este tipo de construção, tanto em Stravinsky quanto em Stein, consiste em uma alternativa surpreendente aos procedimentos musicais do romantismo do século XIX. Trata-se de uma solução verdadeiramente moderna, que estabelece um tipo novo de narratividade com grande potencial musical (ver Zampronha, 2004, p. 76-77).

Na composição, a construção rítmica foi comprimida em um elemento mínimo, ultraconcentrado. Como pode ser observado na Fig. 6, o ritmo foi reduzido à figura "a" (uma sucessão mínima de dois sons percussivos com somente duas alturas, aqui representadas por dois quadrados). Todo o restante é um prolongamento truncado e assimétrico deste evento inicial, que se desdobra em novas figuras:

"a1" é duas vezes a apresentação de "a" onde o segundo quadrado é substituído por um silêncio. Como escutamos " $a$ " imediatamente antes, a introdução dos silêncios é claramente perceptível, gerando um evidente truncamento.

-“a2" é uma ampliação: os dois quadrados que formam "a" aparecem completos, mas o segundo quadrado é repetido de forma insistente. "a".

-"a3" é uma ampliação por antecipação: um exemplar do segundo quadrado antecede a figura

-"a4" é "a" dilatado.

A segunda sequência apresentada na Fig. 5 segue o mesmo procedimento, e inclui algumas simetrias em um contexto assimétrico e truncado, intensificando a sensação de assimetria pelo contraste que estabelece. 

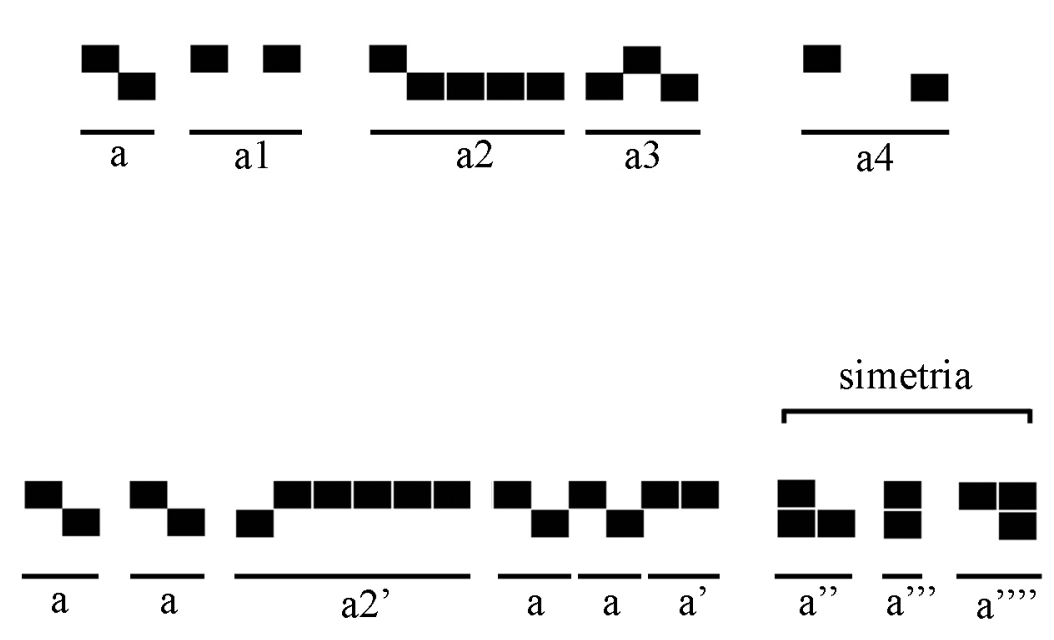

Figura 5. Diagrama da estrutura rítmica de dois segmentos da música, composta por Edson Zampronha, ilustrando ampliações, subtrações, inversões, antecipações e simetrias realizadas de maneira análoga ao texto de Gertrude Stein.

(Diagrama Edson Zampronha).

Um dos principais desafios enfrentados está relacionado à interrupção deste desdobramento sucessivo de maneira convincente e consistente, já que ele poderia prosseguir indefinidamente. Um dos procedimentos utilizados por Gertrude, com maior traduzibilidade em música, consiste em introduzir um elemento novo " $b$ ", que, ao mesmo tempo, interrompe o movimento anterior e inicia novas variações. Estas novas variações, no entanto, podem incluir elementos que já haviam aparecido, realizando interpenetrações de fragmentos, uns nos outros, ou pode simplesmente servir para finalizar os desdobramentos sucessivos. Esta estratégia foi amplamente utilizada na música deste espetáculo.

Em um procedimento característico de Stein, um certo núcleo se mantém mais ou menos estável -- uma sequência-chave de palavras aparece no início do texto e é conservada, enquanto ganha novos matizes. Novas palavras aparecem, e a sequência-chave se torna cada vez mais diversificada. O leitor é gradativamente conduzido a uma zona ambígua, e oscila entre a materialidade do signo e possíveis campos semânticos. Como resultado, a atenção retorna à materialidade do signo, seu veículo, de forma que este, e sua fisicalidade, se converte no tema principal. A música recria este processo através de uma escuta orientada à fisicalidade do signo, com foco no timbre, o objeto sonoro em si mesmo.

Os procedimentos explicados foram utilizados de maneira a não permitir a formação de figuras, motivos, e frases. Em outras palavras, estas identidades musicais não aparecem. Tais procedimentos orientam esteticamente a composição musical. A tradução intersemiótica se revela mais do que uma recriação de procedimentos compositivos para a música; trata-se, antes, da tradução de um objetivo estético, cujos procedimentos de realização se relacionam aos procedimentos identificados no texto de Gertrude Stein.

Sumariamente, os elementos fundamentais para a composição musical, em relação ao texto de Gertrude Stein, são:

(1) um critério formal: uma sucessão de eventos A, B, C e D permutados, variados e 
'truncados' (uma sequência-chave de Gertrude Stein) com constantes referencias cruzadas;

(2) uma estratégia de desdobramento de materiais sonoros por ampliações subtrações, inversões, truncamentos e irregularidades baseadas nos procedimentos de Stein (caso de ritmos ilustrados na Fig. 6), e

(3) uma estratégia para fixar a atenção na materialidade do signo (objeto sonoro em si mesmo), impedindo o aparecimento de um motivo, frase ou forma reconhecível.

\section{Espaço e Luz}

O espaço cênico foi estruturado por vinte e cinco lâmpadas, penduradas por cabos de energia, suspensas a 1,25m de distância do chão e 1,5 m de distância entre si, criando uma matriz de $6 \mathrm{~m} \times 6 \mathrm{~m}$, e um espaço de atuação de 7,5m por 7,5m, devido à difusão da luz (Fig. 6). Todas as lâmpadas foram envoltas por 'camisinhas de lampião', recurso que tornou a fonte de luz homogênea, sem tornar visível o filamento.
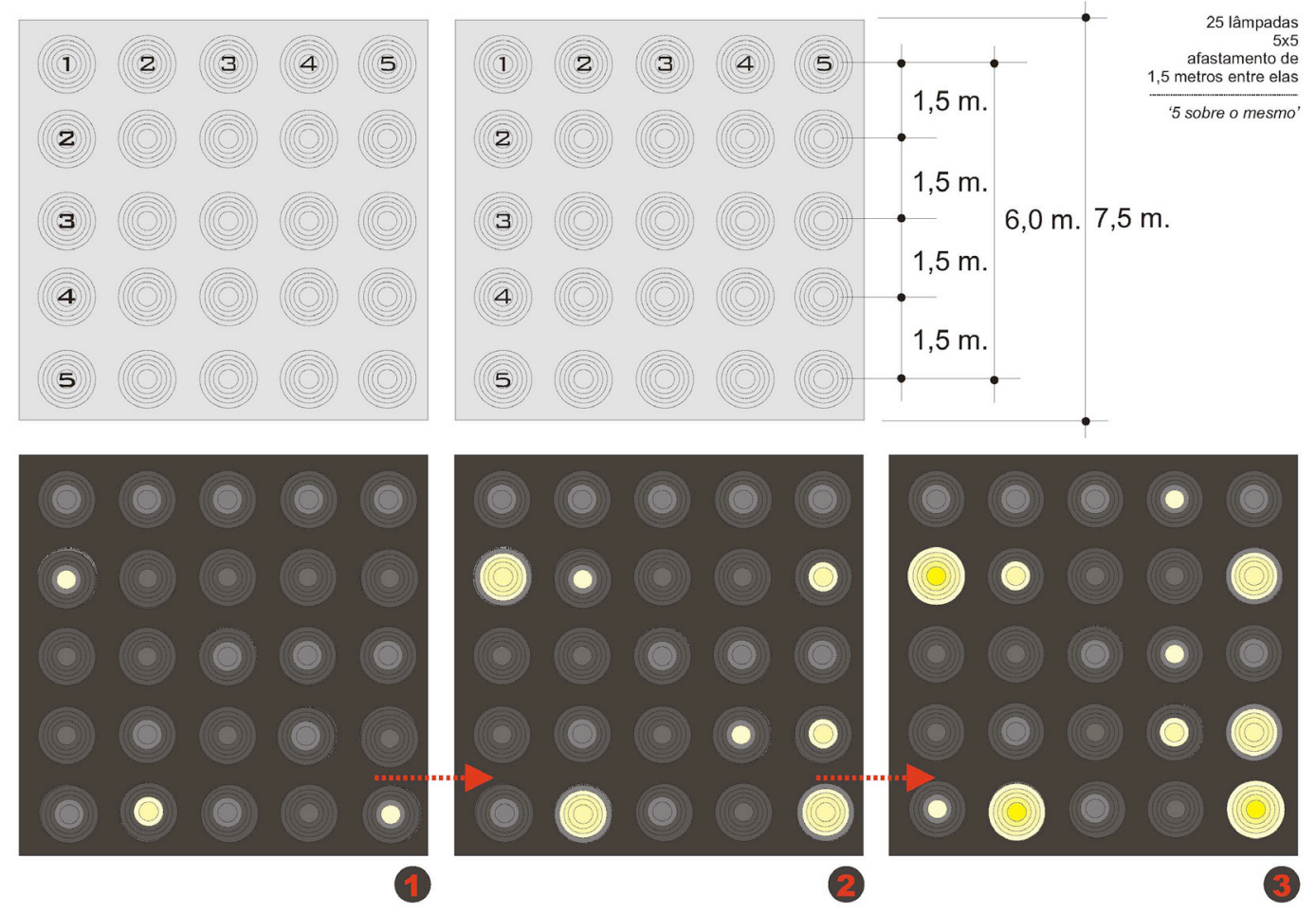

Fig. 6. Mapa de distribuição e funcionamento das lâmpadas no espaço. (Diagrama Adriano Mattos Corrêa).

Na concepção original, as luzes deveriam acender e apagar em tempos distintos e com intensidades diferentes (Fig. 7). No início, a intensidade deveria ser muito baixa aumentando gradativamente até alcançar a capacidade máxima e queimar. Entretanto, os mecanismos para criar esta diferença de intensidade, e de tempo ou dinâmica de atuação, entre as lâmpadas, tornouse operacionalmente impossível de projetar. A solução para criar esta variação, de intensidades e tempos, baseou-se na alternância de procedimentos randômicos e aplicação de regras rígidas. Cinco grupos de cinco lâmpadas foram sorteados em cada apresentação, conferindo ao espaço um padrão de deslocamentos, e comportamento, imprevistos. Foram criadas diferentes partituras sobre 
o comportamento destes grupos, interpretadas pelo operador de luz, em cada apresentação. Deste modo, tornou-se impossível o estabelecimento de qualquer hábito sobre o comportamento da luz, tornando-a um domínio independente da música e dos intérpretes.

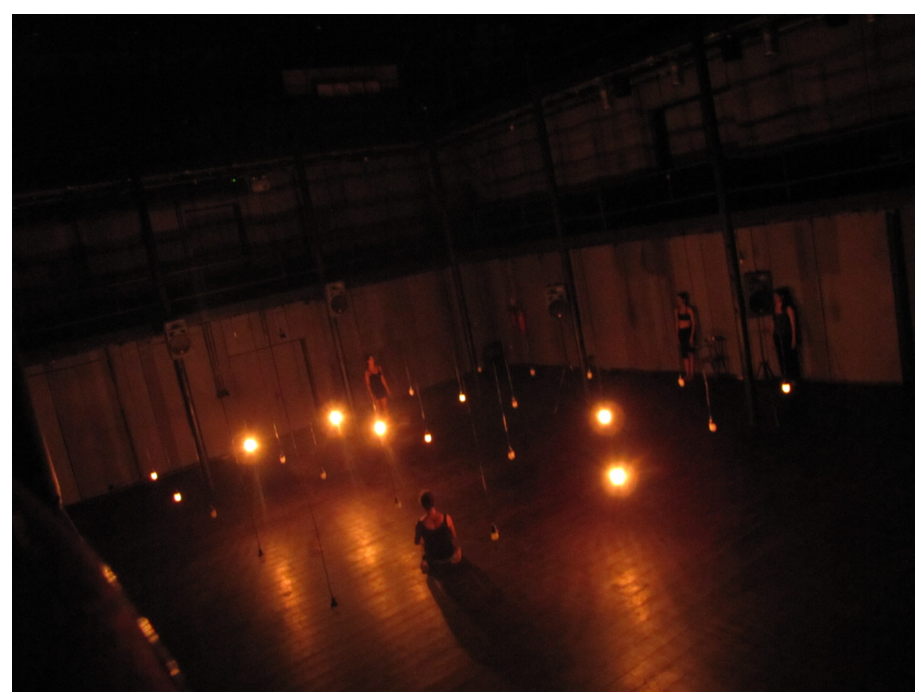

Fig. 7. Iluminação em funcionamento no Teatro Vila Velha durante ensaio geral. (Fotografia Adriano Mattos Corrêa).

\section{Composição}

No dia 23 de fevereiro de 2010, a equipe integrada pelos criadores-intérpretes, o arquiteto, o coordenador do projeto e a produção, encontraram-se pela primeira vez para mostrar seus resultados coletivamente. Em quatro dias foram exibidos os resultados individuais, realizadas diversas experiências e tomadas decisões sobre o formato de apresentação dos resultados. Foram exibidas, pela primeira vez aos criadores-intérpretes, a música original e a concepção da iluminação. $\mathrm{O}$ principal desafio para a equipe foi articular os resultados individuais, e transformar em algo coerente os fragmentos criados separadamente. O primeiro encontro deixou claro que a toda variedade de soluções combinadas criaria dificuldades de outra magnitude -- arranjo entre os resultados. Imaginávamos, antes do encontro, que criaríamos, mais facilmente, um espaço de aproximações quase-naturais entre as resultados individuais. Mas não foi assim. Cada criador-intérprete estava equipado com suas próprias convicções sobre como deve se comportar um "espetáculo", o acontecimento mais macroscópico que reúne muitas coisas (música, luz, figurino, etc.).

Inicialmente estudamos a opção de uma coreografia estruturada e definida. Ela seria composta a partir do reconhecimento de similitudes estruturais entre os resultados individuais, formando duos e trios. Deste modo, criaríamos uma relação de transição entre cada duo ou trio, baseada em três tipos de transição: justaposição (quando um acaba, outro começa), superposição (antes de acabar, o outro inicia) e separação (tempo entre o final de um e o começo do outro).

Entretanto, ao experimentarmos diferentes propostas, optamos por um formato entre uma composição pré-estabelecida e uma composição em tempo real. Criamos um roteiro geral, que definia diversos aspectos, como períodos de música e silêncio, e alguns materiais de criadores-intérpretes em momentos específicos. Do mesmo modo, o roteiro definia momentos de composição em tempo real.

Ao final de quatro dias de encontro agrupamos os resultados individuais mantendo, ao mesmo tempo, a coerência geral e a independência dos resultados individuais dos criadoresintérpretes, do compositor e do arquiteto. Também utilizamos os dias de apresentação para ajustar 
estas relações. Assim, o roteiro foi modificado até o último dia de apresentação, de maneira mais ou menos perceptível para a plateia.

\section{Considerações Finais}

Notavelmente, as traduções do signo-fonte não foram orientadas para uma única região de referência (a própria fonte), mas tiveram desenvolvimentos independentes, dificilmente conciliáveis em um espetáculo. Esta dificuldade, no entanto, converteu-se na característica mais especial de construção do espetáculo -- em sua forma final, a iluminação, a distribuição dos objetos, os segmentos musicais, o arranjo temporal das séries motoras, a natureza das transições e das pausas respeitam as leituras de cada tradução realizada por cada participante e, ao mesmo tempo, se unem de forma diferente em cada apresentação, colocando em primeiro plano a organização paratática. Acaso e determinação são combinados de tal forma que cada apresentação assume um caráter singular. As diferentes leituras se associam e, através de relações icônicas especiais, se amplificam, produzindo uma leitura global sempre distinta. A apresentação simultânea das diferentes leituras do textofonte no espetáculo tem uma forma des-hierarquizada que atinge todos os níveis do espetáculo. Em outras palavras, a “des-hierarquização" atingiu todos os níveis do espetáculo, entre a música, dançarinos, espaço cênico, luz, etc., e reinstaurou-se em cada apresentação, forçando seus integrantes a experimentar como uma "novidade" a parataxe estrutural que caracteriza, segundo Stein, a contribuição fundamental de Cézanne.

Agradecimento: Daniella Aguiar agradece à CAPES pelo apoio recebido através da bolsa de pósdoutorado.

\section{Referências}

AGUIAR, Daniella. Da literatura para a dança: a prosa-poética de Gertrude Stein em tradução intersemiótica. Tese de doutorado - Literatura Comparada. Instituto de Letras, Universidade do Estado do Rio de Janeiro, Rio de Janeiro, 2013.

STEIN, Gertrude. Gertrude Stein and Her Brother, and Other Early Portraits. New Haven: Yale University Press, 1951.

BRIDGMAN, Richard. Gertrude Stein in pieces. New York: Oxford University Press, 1970. 411 p.

JAKOBSON, Roman. Linguística e comunicação. São Paulo: Cultrix, 1969.

GORLÉE, Dinda L. Bending back and breaking. Symploke, v. 15, n. 1-2, p. 341-352, 2007.

CLÜVER, Claus. Estudos interartes: conceitos, termos, objetivos. Literatura e Sociedade: Revista de teoria literária e literatura comparada, São Paulo, n. 2, p. 37-55, 1997.

PLAZA, Julio. Tradução intersemiótica. São Paulo: Perspectiva, 1987.

STEINER, Wendy. Exact Resemblance to Exact Resemblance: The Literary Portraiture of Gertrude Stein. New Haven: Yale University Press, 1978.

WALKER, Jane L. The making of a modernist: Gertrude Stein from Three lives to tender buttons. Amherst: The University of Massachusetts Press, 1984. 
ZAMPRONHA, Edson. A Construção do Sentido Musical. In: Maria de Lourdes Sekeff e Edson Zampronha (Org.), Arte e Cultura III - estudos transdisciplinares. São Paulo: Annablume/FAPESP, 2004. p.75-84.

ZAMPRONHA, Edson. Da escuta do objeto sonoro à composição musical? Um estudo sobre a irreversibilidade da escuta em composição. Ouvirouver, Uberlândia: Universidade Federal de Uberlândia, V.7, 2011.

Online em: http://www.zampronha.com/Texts/2011_OuvirOuVer_Zampronha.pdf

\section{Anexo:}

\section{Orta ou alguém dançando}

Gertrude Stein (c. 1911-12); tradução Luci Collin.

Mesmo que uma fosse uma ela poderia ser como alguma outra. Ela era como uma e então era como uma outra e então era como uma outra e então era como uma outra e então era uma que era uma tendo sido uma e sendo uma que era uma então, uma sendo como algumas.

Mesmo que ela fosse uma e ela era uma, mesmo que ela fosse uma ela estava mudando. Ela era uma e era então como alguma uma. Ela era uma e tinha então vindo a ser como algumas outras uma. Ela era então uma e tinha vindo então a ser como algumas outras uma. Ela era então uma e tinha vindo então a ser como algumas outras uma. Ela era então uma e tinha vindo então a ser como um tipo de uma uma.

Mesmo que ela fosse uma sendo uma, e ela era uma sendo uma, ela era uma sendo uma e mesmo que ela fosse uma sendo uma ela era uma que estava então sendo um tipo de uma uma.

Mesmo que ela fosse uma sendo uma e ela estava sendo uma sendo uma, mesmo que ela fosse uma sendo uma ela era uma vindo a ser uma de um outro tipo de uma uma.

Mesmo que ela estivesse então sendo uma e ela era então uma sendo uma, mesmo que ela estivesse então sendo aquela uma ela era uma sendo, ela era uma que tinha vindo a ser uma sendo de um outro tipo de uma uma.

Mesmo que ela fosse uma sendo uma e ela era uma sendo uma, mesmo que ela fosse uma sendo aquela uma ela era uma sendo ela era então um outro tipo de uma uma, ela estava então sendo um outro tipo de uma uma.

Mesmo que ela fosse uma sendo uma, mesmo que ela fosse uma sendo uma e sendo aquela uma ao ser uma, mesmo que ela estivesse sendo aquela que ela estava sendo ao ser aquela uma, mesmo que ela estivesse sendo aquela uma ela estava sendo um tipo de uma uma ela estava vindo a ser de um tipo de uma uma, ela estava vindo a ser bem de um tipo de uma uma.

Fragmento de STEIN, G. Gertrude Stein and Her Brother, and Other Early Portraits. New Haven: Yale University Press, 1951. CTradução Luci Collin, 2004. 